\title{
MENENTUKAN NILAI PRODUKSI INDUSTRI ROTAN CV. BUDI MULYA DENGAN MENGGUNAKAN METODE DEKOMPOSISI LU PADA MODEL EKONOMI LEONTIEF
}

\author{
I. Werokati ${ }^{1}$, S. Musdalifah², A. Hendra ${ }^{3}$ \\ 1,2Prodi Matematika Jurusan Matematika FMIPA UNTAD \\ 2Jurusan Tekhnik Informatika Fakultas Tekhnik UNTAD \\ Kampus Bumi Tadulako Tondo \\ Jl.Soekarno Hatta Km.9, Palu, 94118, Indonesia \\ 1bsakura77@yahoo.co.id ,2selvymusdalifah@yahoo.com,33a_for_andie@icloud.com
}

\begin{abstract}
Abstrak
Industri rotan Cv. Budi Mulya merupakan industri yang cukup berkembang di kota Palu. Dalam menjalankan produksinya dibutuhkan industri lain yaitu industri peralatan, industri listrik dan industri minyak dan gas. Untuk menjaga keseimbangan dan kelangsungan industri rotan tersebut dan ketiga industri yang terlibat dalam proses produksinya industri - industri tersebut harus melakukan produksi dengan jumlah yang tepat. Penelitian ini menggunakan metode Dekomposisi LUPada Model Ekonomi Leontief untuk mendapatkan nilai produksi industri rotan pada Cv. Budi Mulya dan industri-industri lain yang terlibat pada proses produksinya. Dari hasil penelitian diperoleh nilai produksi tahun 2011 untuk industri rotan Cv. Budi Mulya sebesar 28,134539 juta rupiah, industri peralatansebesar 16,650031 juta rupiah, industri listrik sebesar 19,96078 juta rupiah dan industri minyak dan gas sebesar 25,475373 juta rupiah.
\end{abstract}

Kata kunci $\quad$ : Industri rotan, Metode Dekomposisi LU, Model Ekonomi Leontief, Nilai produksi.

\section{Pendahuluan}

Besarnya potensi rotan di Sulawesi Tengah ini, mendorong berkembangnya industri pengolahan rotan mentah menjadi rotan polis dan rotan core di Kota Palu salah satunya adalah industri rotan Cv. Budi Mulya. Cv. Budi Mulya ini memproduksi perabotan rumah tangga, meliputi: seperangkat meja-kursi tamu, meja-kursi makan, kursi goyang, kursi santai serta berbagai macam rak dan barang-barang hiasan. Pada umumnya industri rotan ini membuat semua jenis barang. Dalam hal ini industri listrik, industri peralatan mesin, industri minyak dan gas berperan penting dalam penyediaan input pada proses pengolahan rotan dan untuk menjaga keseimbangan dan 
kelangsungan industri rotan dan ketiga industri lain tersebut maka semua industri tersebut harus melakukan produksi dengan jumlah yang tepat.

Dalam ekonomi, menentukan jumlah produksi untuk masalah seperti ini ditangani dengan suatu model matematika yaitu model Ekonomi Leontief. Model Ekonomi Leontief memodelkan pencarian solusi jumlah yang harus diproduksi oleh industri dalam bentuk sistem persamaan linear.

Metode Dekomposisi LU dikenal sebagai metode penyelesaian sistem persamaan linear bersifat langsung (Direct Method) yang cukup efisien. Dekomposisi LU adalah cara penyelesaian sistem persamaan linear dengan terlebih dahulu menfaktorkan matriks sistem persamaan linear menjadi dua matriks, matriks pertama adalah matriks segitiga bawah dengan diagonal semua bernilai satu, sedangkan matriks kedua adalah matriks segitiga atas metode ini akan dirancang dan dianalisis sehingga cocok untuk diterapkan dalam penyelesaian model Ekonomi Leontief ini (Noorcahyo,2010).

\section{Metode Penelitian}

Data yang digunakan berupa data sekunder dari industri rotan Cv. Budi Mulya dan ketiga industri lain yang terlibat dalam proses produksinya pada tahun 2011. Dan adapun jenis data yang digunakan dalam penelitian ini adalah data kuantitatif yaitu berupa data konsumsi industri rotan $\mathrm{Cv}$. Budi Mulya dan ketiga industri lain yang terlibat dalam proses produksinya pada tahun 2011. Sedangkan prosedur pada penelitian ini adalah :

1. Memulai Penelitian

2. Melakukan studi literatur dengan mengumpulkan materi dari buku-buku, artikel dan jurnal yang di dapat dari perpustakaan dan perpustakaan online.

3. Menganalisa masalah.

4. Mengumpulkan beberapa data dari berbagai sumber yang ada.

5. Pembuatan matriks konsumsi

6. Mengubah matriks konsumsi kedalam Model Ekonomi Leontief

7. Menentukan nilai produksi industri rotan Cv. Budi Mulya dan ketiga industri yang terlibat dalam proses produksinya menggunakan Metode Dekomposisi LU pada Model Ekonomi leontief.

8. Hasil penelitian

9. Kesimpulan

10. Selesai 


\section{Hasil dan Pembahasan}

\subsection{Hasil Penelitian}

Industri rotan Cv. Budi Mulya termasuk industri menengah di kota Palu yang memproduksi rotan mentah menjadi produk stengah jadi (komponen) berupa rotan kulit (iratan), rotan hati (core) dan juga menghasilkan produk jadi berupa produk-produk mebel, rak-rak (pakaian dan buku) keranjang, aneka anyaman rotan dan sebagainya. Dalam melakukan proses produksinya industri rotan membutuhkan beberapa produk dari industri peralatan mesin, industri listrik dan industri minyak dan gas. Demikian juga ketiga industri tersebut saling membutuhkan dalam menjalankan proses produksi masing-masing. Kebutuhan industri-industri tersebut tertulis dalam data konsumsi untuk satu kali produksi tahun 2011 pada industri rotan Cv. Budi Mulya tahun 2011 dan ketiga industri lain yang terlibat pada proses produksinya. Data tersebut sebagai berikut :

Tabel 1: Data Konsumsi dalam Satu Kali Produksi Tahun 2011

\begin{tabular}{|c|c|c|c|c|}
\hline No & $\begin{array}{c}\text { Industri Rotan } \\
(\mathrm{Rp})\end{array}$ & $\begin{array}{c}\text { Industri peralatan } \\
(\mathrm{Rp})\end{array}$ & $\begin{array}{c}\text { Industri listrik } \\
(\mathrm{Rp})\end{array}$ & $\begin{array}{c}\text { Industri Minyak } \\
\text { dan Gas } \\
(\mathrm{Rp})\end{array}$ \\
\hline $\begin{array}{c}\text { Industri Rotan } \\
\begin{array}{c}\text { Industri Peralatan } \\
\text { Mesin }\end{array}\end{array}$ & 550.000 & 450.000 & 119.000 & 252.000 \\
\hline Industri Listrik & 0 & 542.000 & 215.000 & 125.000 \\
\hline $\begin{array}{c}\text { Industri Minyak dan } \\
\text { gas }\end{array}$ & 0 & 321.000 & 427.000 & 225.000 \\
\hline
\end{tabular}

\subsection{Pembuatan Matriks Konsumsi}

Dari data konsumsi diatas terbentuklah matriks konsumsi sebagai berikut :

$$
\mathrm{A}=\left[\begin{array}{cccc}
0,055 & 0,0425 & 0,0119 & 0,0252 \\
0, & 0,0542 & 0,0215 & 0,0125 \\
0 & 0,0321 & 0,0427 & 0,0225 \\
0 & 0,0345 & 0,0235 & 0,051
\end{array}\right]
$$

Permintaan dari luar (permintaan pasar) pada tahun 2011 untuk industri rotan dan ketiga industri lainnya adalahsebagai berikut :

$$
\mathrm{b}=\left[\begin{array}{l}
25 \\
15 \\
18 \\
23
\end{array}\right]
$$

\subsection{Pemodelan Matriks Konsumsi Kedalam Model Ekonomi Leontief}

$$
(\mathrm{I}-\mathrm{A}) \mathbf{p}=\mathbf{b}
$$




$$
\begin{gathered}
{\left[\begin{array}{llll}
1 & 0 & 0 & 0 \\
0 & 1 & 0 & 0 \\
0 & 0 & 1 & 0 \\
0 & 0 & 0 & 1
\end{array}\right]-\left[\begin{array}{cccc}
0,055 & 0,0425 & 0,0119 & 0,0252 \\
0, & 0,0542 & 0,0215 & 0,0125 \\
0 & 0,0321 & 0,0427 & 0,0225 \\
0 & 0,0345 & 0,0235 & 0,051
\end{array}\right]=\left[\begin{array}{l}
\mathrm{p}_{1} \\
\mathrm{p}_{2} \\
\mathrm{p}_{3} \\
\mathrm{p}_{4}
\end{array}\right]=\left[\begin{array}{l}
25 \\
15 \\
18 \\
23
\end{array}\right]} \\
{\left[\begin{array}{cccc}
0,945 & -0,0425 & -0,0119 & -0,0252 \\
0 & 0,9458 & -0,0215 & -0,0125 \\
0 & -0,0321 & 0,9573 & -0,0225 \\
0 & -0,0345 & -0,0235 & 0,949
\end{array}\right]}
\end{gathered}
$$

\subsection{Penerapan Metode Dekomposisi LU}

Jika matriks A non-singular maka ia dapat difaktorkan (diuraikan atau didekomposisi) menjadi segitiga bawah L (lower) dan matriks segitiga atas $U$ (upper) (http://dianpraja.files.wordpress.com/2012/10/metnum-week91.pptx). Langkah-langkah penentuan solusi p dengan menggunakan metode dekomposisi LU adalah sebagai berikut :

\subsubsection{Menfaktorkan Matriks Konsumsi (A) Menjadi Matriks LU}

Matriks hasil pengurangan dari matriks identitas dan Matriks konsumsi (I - A) menjadi matriks utama dari sistem persamaan linear. Matriks ini difaktorkan menjadi matriks segitiga bawah $\mathrm{L}$ (lower) dan matriks segitiga atas $\mathrm{U}$ (upper). Pada matriks segitiga bawah L, semua elemen diagonal bernilai 1 sedangkan pada matriks segitiga atas $U$ tidak ada aturan khusus pada elemen diagonalnya.

$\mathrm{A}=\left[\begin{array}{cccc}0,945 & -0,0425 & -0,0119 & -0,0252 \\ 0 & 0,9458 & -0,0215 & -0,0125 \\ 0 & -0,0321 & 0,9573 & -0,0225 \\ 0 & -0,0345 & -0,0235 & 0,949\end{array}\right]$

Matriks A difaktorkan menjadi matriks $L$ dan $U$. Adapun algoritma dekomposisi LU sebagai berikut :

Baris 1 :

$$
\begin{aligned}
& \mathrm{u}_{11}=\mathrm{a}_{11}=0,945 \\
& \mathrm{u}_{12}=\mathrm{a}_{12}=-0,0425 \\
& \mathrm{u}_{13}=\mathrm{a}_{13}=-0,0119 \\
& \mathrm{u}_{14}=\mathrm{a}_{14}=-0,0252
\end{aligned}
$$

\section{Baris 2 :}

Pengisian matriks $L$ :

$\mathrm{l}_{21}=\frac{\mathrm{a}_{21}}{\mathrm{u}_{11}}=\frac{0}{0,945}=0$

Pengisian matriks $U$ :

$$
\begin{aligned}
\mathrm{u}_{22} & =\mathrm{a}_{22}-\mathrm{l}_{21} \mathrm{u}_{12} \\
& =0,9458-0 \\
& =0,9458 \\
\mathrm{u}_{23} & =\mathrm{a}_{23}-\mathrm{l}_{21} \mathrm{u}_{13} \\
& =-0,0215-0 \\
& =-0,0215
\end{aligned}
$$




$$
\begin{aligned}
\mathrm{u}_{24} & =\mathrm{a}_{24}-\mathrm{l}_{21} \mathrm{u}_{14} \\
& =-0,0125-0 \\
& =-0,0125
\end{aligned}
$$

Baris 3 :

Pengisian matriks $L$ :

$$
\begin{aligned}
& \mathrm{l}_{31}=\frac{\mathrm{a}_{31}}{\mathrm{u}_{11}}=\frac{0}{0,945}=0 \\
& \mathrm{l}_{32}=\frac{\left(\mathrm{(}_{32}-\mathrm{l}_{31} \mathrm{u}_{12}\right)}{\mathrm{u}_{22}}=\frac{-0,0321}{0,9458}=-0,03394
\end{aligned}
$$

Pengisian matriks $U$ :

$$
\begin{aligned}
\mathrm{u}_{33} & =\mathrm{a}_{33}-\mathrm{l}_{31} \mathrm{u}_{13}-\mathrm{l}_{32} \mathrm{u}_{23} \\
& =0,9573-0-0,00072971 \\
& =0,95657029 \\
\mathrm{u}_{34} & =\mathrm{a}_{34}-\mathrm{l}_{31} \mathrm{u}_{14}-\mathrm{l}_{32} \mathrm{u}_{24} \\
& =-0,0225-0-0,00042425 \\
& =-0,02292425
\end{aligned}
$$

Baris 4 :

Pengisian matriks L :

$$
\begin{aligned}
\mathrm{l}_{41} & =\frac{\mathrm{a}_{41}}{\mathrm{u}_{11}} \\
& =\frac{0}{0,945}=0 \\
\mathrm{l}_{42} & =\frac{\mathrm{a}_{42}-\mathrm{l}_{41} \mathrm{u}_{12}}{\mathrm{u}_{22}}=\frac{-0,0345-0}{0,9458}=-0,0365 \\
\mathrm{l}_{43} & =\frac{\mathrm{a}_{43}-\mathrm{l}_{41} \mathrm{u}_{13}-\mathrm{l}_{42} \mathrm{u}_{23}}{\mathrm{u}_{33}}=\frac{-0,0235-0-0,00074175}{0,95657029}=-0,02534
\end{aligned}
$$

Pengisian matriks $U$ :

$\mathrm{u}_{44}=\mathrm{a}_{44}-\mathrm{l}_{41} \mathrm{u}_{14}-\mathrm{l}_{42} \mathrm{u}_{24}-\mathrm{l}_{43} \mathrm{u}_{34}=0,949-0-0,00045625-0,00581=0,942734$

Diperoleh matriks $\mathrm{L}$ dan $\mathrm{U}$ :

$$
\begin{aligned}
\mathrm{L} & =\left[\begin{array}{cccc}
1 & 0 & 0 & 0 \\
0 & 1 & 0 & 0 \\
0 & -0,03394 & 1 & 0 \\
0 & -0,0365 & -0,02534 & 1
\end{array}\right] \\
\mathrm{U} & =\left[\begin{array}{cccc}
0,945 & -0,425 & -0,019 & -0,0252 \\
0 & 0,9458 & -0,0215 & -0,0125 \\
0 & 0 & 0,9565 & -0,0229 \\
0 & 0 & 0 & 0,942734
\end{array}\right]
\end{aligned}
$$

\subsubsection{Penyelesaian $\mathrm{Lz}=\mathbf{b}$}

Matriks L yang didapatkan dari dekomposisi matriks identitas dikurangi matriks konsumsi dari industri rotan dan ketiga industri lainnya ( $\mathrm{I}-\mathrm{A}$ ) dimanfaatkan terlebih dahulu dengan membentuk suatu sistem persamaan linear bersama dengan vector demand $\mathbf{b}$. Sistem persamaan lanjar ini akan menghasilkan $\boldsymbol{z}$ yang merupakan vektor perantara dalam pencarian solusi p. Penyelesaian sistem persamaan linear ini dilakukan dengan teknik penyulihan maju. 


$$
\begin{aligned}
& \mathrm{L}=\left[\begin{array}{cccc}
1 & 0 & 0 & 0 \\
0 & 1 & 0 & 0 \\
0 & -0,03394 & 1 & 0 \\
0 & -0,0365 & -0,02534 & 1
\end{array}\right]\left[\begin{array}{l}
\mathrm{z}_{1} \\
\mathrm{z}_{2} \\
\mathrm{z}_{3} \\
\mathrm{z}_{4}
\end{array}\right]=\left[\begin{array}{l}
25 \\
15 \\
18 \\
23
\end{array}\right] \\
& \mathrm{l}_{\mathrm{z}}=\mathrm{b} \mathrm{z}_{1}=25 \\
& \mathrm{z}_{2}=15 \\
&-0,03394 \mathrm{z}_{2}+\mathrm{z}_{3}=18 \\
& \mathrm{z}_{3}=18+0,03394(15) \\
& \mathrm{z}_{3}=18+0,5091 \\
& \mathrm{z}_{3}=18,5091 \\
&-0,0365 \mathrm{z}_{2}-0,02534 \mathrm{z}_{3}+\mathrm{z}_{4}=23 \\
&-0,5475-0,4690+\mathrm{z}_{4}=23 \\
& \quad=23+0,5475+0,4690 \\
& \mathrm{z}_{4}=24,0165
\end{aligned}
$$

Dari hasil perhitungan menggunakan tehnik penyulihan maju maka diperoleh matriks perantara $\mathbf{z}$ yaitu :

$$
\mathbf{z}=\left[\begin{array}{c}
25 \\
15 \\
18,5091 \\
24,0165
\end{array}\right]
$$

Solusi perantara yang sudah diperoleh akan digunakan untuk menyelesaikan $U_{\mathbf{p}}=\mathbf{z}$ sehingga kita akan mendapatkan solusi $\mathbf{p}$ yang merupakan nilai produksi yang harus diproduksi oleh industri rotan Cv. Budi Mulya dan ketiga industri lainnya yang terlibat dalam proses produksinya sehingga total konsumsi masing-masing industri dan permintaan dari luar (permintaan pasar) terpenuhi.

\subsubsection{Penyelesaian $U \mathbf{p}=\mathbf{z}$}

Setelah kita peroleh solusi perantara $\mathbf{z}$ maka kita dapat mencari solusi nilai produksi $\mathbf{p}$ dari persamaan $\mathbf{U p}=\mathbf{z}$ dengan melakukan teknik penyulihan mundur.

$$
\mathrm{U}=\left[\begin{array}{cccc}
0,945 & -0,0425 & -0,019 & -0,0252 \\
0 & 0,9458 & -0,0215 & -0,0125 \\
0 & 0 & 0,9565 & -0,0229 \\
0 & 0 & 0 & 0,942734
\end{array}\right]\left[\begin{array}{l}
p_{1} \\
p_{2} \\
p_{3} \\
p_{4}
\end{array}\right]=\left[\begin{array}{c}
25 \\
15 \\
18,5091 \\
24,0165
\end{array}\right]
$$

\section{Baris 4 :}

$0,942734 \mathrm{p}_{4}=24,0165$

$$
\begin{aligned}
& \mathrm{p}_{4}=\frac{24,0165}{0,942734} \\
& \mathrm{p}_{4}=25,475373
\end{aligned}
$$

\section{Baris 3 :}

$0,9565 p_{3}-0,0229 p_{4}=18,5091$

$0,9565 p_{3}-0,58338604=18,5091$

$$
\mathrm{p}_{3}=\frac{19,092486}{0,9565}=19,96078
$$


Baris 2:

$0,9458 p_{2}-0,0215 p_{3}-0,0125 p_{4}=15$

$0,9458 p_{2}-0,42915677-0,31844216=15$

$$
\mathrm{p}_{2}=\frac{15,747599}{0,9458}=16,650031
$$

Baris 1:

$0,945 \mathrm{p}_{1}-0,0425 \mathrm{p}_{2}-0,019 \mathrm{p}_{3}-0,0252 \mathrm{p}_{4}=25$

$0,945 p_{1}-0,7076263-0,23753328-0,6419794=25$

$$
\mathrm{p}_{1}=\frac{26,587139}{0,945}=28,134539
$$

Dari hasil perhitungan diperoleh solusi nilai produksi (p) dari industri rotan Cv. Budi Mulya dan ketiga industri lain yang terlibat dalamsatu kali proses produksinya tahun 2011 yaitu :

$p=\left[\begin{array}{c}28,134539 \\ 16,650031 \\ 19,96078 \\ 25,475373\end{array}\right]$

\section{Kesimpulan}

Dari pengerjaan secara manual menggunakan metode Dekomposisi LU pada Model Ekonomi Leontief diperoleh nilai output produksi dari industri Cv. Budi Mulya dan ketiga industri yang terlibat dalam satu kali proses produksinya pada tahun 2011 yaitu nilai produksi industri rotan pada Cv. Budi Mulya sebesar 28,134539juta rupiah, nilai produksi peralatan mesin sebesar 16,650031juta rupiah, nilai produksi industri listrik sebesar 19,96078 juta rupiah, nilai produksi minyak dan gas sebesar 25,475373 juta rupiah.

\section{Daftar Pustaka}

[1]. ( http://dianpraja.files.wordpress.com/2012/10/metnum-week91.pptx).

[2]. Noorcahyo. A. D. 2010. Penggunaan Metode Dekomposisi LU Untuk Penentuan Produksi Suatu Industri Dengan Model Ekonomi Leontief. Informatika. 